\title{
The Use of a Diagnostic Database in Clinical Oncogenetics
}

\author{
Rolf H. Sijmons', Gerard T.N. Burger ${ }^{2}$ \\ 'Department of Clinical Genetics, Groningen University Hospital, Groningen; ${ }^{2}$ Department of Pathology, SAZINON Foundation, Bethesda Hospital, Hoogeveen, The Netherlands
}

Key words: hereditary cancer, familial cancer, differential diagnosis, database, software, computer-assisted diagnosis

Corresponding author: Rolf H. Sijmons, MD PhD, Department of Clinical Genetics, Groningen University Hospital, P.O. Box 30.001, 9700 RB Groningen, The Netherlands, Phone: +31 50 3632925, fax: +31 50 3632457,

e-mail: r.h.sijmons@medgen.azg.nl,web site:www.facd.info

\begin{abstract}
In addition to a relatively small number of well known hereditary cancer syndromes, hundreds of presumed or proven hereditary disorders have been observed to manifest cancer as a characteristic feature or as a possible complication. The recognition of these disorders may be of great importance for the medical management of the families involved. Specialized databases, like the Familial Cancer Database (FaCD, www.facd.info), may be helpful in the making of differential diagnoses and offer advantages compared with traditional textbooks and on-line literature searches. Based on our own experience and interviews with the other Dutch family cancer clinics, we expect that in similar clinics, computer-assisted differential diagnosis will be primarily used in helping to decide whether or not cancer patients and families should be referred to family cancer clinics for further study and counseling. FaCD has been developed as a tool for experts. As general practitioners and other health professionals with non-expert knowledge of cancer genetics are under increasing pressure to advise on genetic risks, it should be encouraged that other software is developed to support them in interpreting family histories of cancer.
\end{abstract}

In addition to a relatively small number of hereditary cancer syndromes generally well known by physicians, genetic nurses and counselors, hundreds of presumed or proven hereditary disorders have been observed to manifest cancer as a characteristic feature or possible complication. The recognition of these disorders may be of great importance for the medical management of the families involved. Understandably, active knowledge on the wide range of less frequent disorders is not as common as that on the more frequent ones. Even some of the health professionals specialized in the field of clinical cancer genetics might find themselves hard pressed to give details, from the top of their hat, on disorders like familial clustering of multiple myeloma, mesothelioma, salivary gland tumors or Sezary syndrome.

Traditionally, textbooks and journal articles are used to help with the making of differential diagnoses, and several valuable textbooks on hereditary cancer have been published [1-5]. These books tend to focus on the more frequent and/or better known tumor syndromes, but have the advantage of direct accessibility. Although journal articles, in toto, cover a much wider range of proven or presumed genetic disorders associated with cancer or familial clusters of cancer, the 'mining' of these articles by hand, or through on-line search engines like PubMed (www.ncbi.nlm.nih.gov/entrez), while hunting for a particular combination of tumors observed in a patient/family may prove difficult and at least timeconsuming.

On the other hand, a database developed with the specific purpose in mind of offering a tool to assist with the making of a differential diagnosis, has the advantage of covering a wide range of literature sources, including older ones not yet available online, as well as presenting a user interface specifically designed to allow easy searching for combinations of clinical features. In the field of clinical genetics, several 
Table 1. Medical Profession of Registered FaCD users. By November 2002, 1114 users from a total of 74 different countries had registered their copy of $\mathrm{FaCD}$ through our web site

\begin{tabular}{lc}
\hline Profession & $\%$ \\
\hline Clinical Geneticist/Genetic Counselor & 36 \\
\hline Medical Oncologist/Internist & 12 \\
\hline Surgeon & 6 \\
\hline Pathologist & 4 \\
\hline Radiation Oncologist & 4 \\
\hline Gastroenterologist & 2 \\
\hline General Practitioner & 2 \\
\hline Pediatrician & 1 \\
\hline Gynaecologist & 1 \\
\hline Other Clinical Specialty & 11 \\
\hline Molecular Geneticist & 9 \\
\hline Scientist, non-clinical & 7 \\
\hline Other & 18 \\
\hline
\end{tabular}

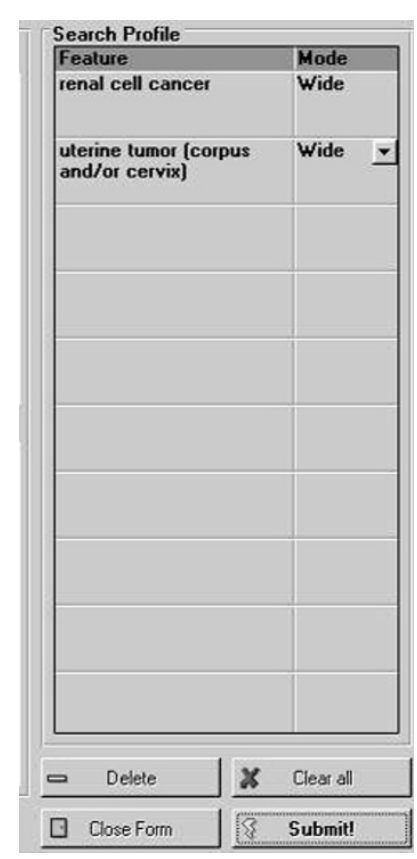

Fig. 1. Screenshot of a search profile, a particular combination of tumor and non-tumor features, entered into FaCD by the user. After submitting the profile, FaCD will return a list of all of its stored syndromes which feature the items entered in the search profile, including published but as yet unproven associations if the user so wishes. In this example, the user has neither specifics on the type of tumor of uterus or cervix nor on the histological subtype of the renal cell cancer of these databases have been developed [6], of which the London Dysmorphology Database [7], POSSUM [8] and the Human Cytogenetics Database [9] are the most widely used ones in genetics clinics. A similar type of database for cancer genetics did not exist until recently when the Familial Cancer Database (FaCD) was developed [10]. In the year 2000, the software was first released, through the internet (www.facd.info), in support of the Familial Cancer and Prevention Program of the UICC (Union Internationale Contre le Cancer, International Union Against Cancer, www.vicc.org).

Unlike expert systems, $\mathrm{FaCD}$ and the other mentioned computer programs do not diagnose conditions, but have a prompting function instead, reminding their users of diagnoses they may not have considered. The software is aimed at users with a level of expertise which enables them to translate the clinical features observed in a patient and his or her family into the correct terminology, distill from those the best "search-handles" [1 1; 12] (e.g. early-onset cancer rather than common cancer with normal age at diagnosis) (Figure 1), interpret the output (Figure 2), retain diagnoses of interest, and discard the others. In the case of $\mathrm{FaCD}$, the software is aimed at health professionals working in family cancer clinics and other clinicians with an active interest in, and knowledge of, hereditary cancer predisposition. These include, in particular, genetic counselors, clinical geneticists and medical and surgical oncologists and, indeed, these are counted among the most frequent registrants of $\mathrm{FaCD}$, as shown in Table 1.

The performance of $\mathrm{FaCD}$ and similar databases should be evaluated by looking at the performance of the user and the software together [13]. Until such studies have been performed, the added value of these databases remain undefined. We have yet to systematically study the use physicians and genetic counselors make of $\mathrm{FaCD}$ in clinical practice, and its possible added value. We can, however, report on the use of $\mathrm{FaCD}$ during the last 3 years in the Groningen Family Cancer Clinic, part of the department of Clinical Genetics of the Groningen University Hospital. On a yearly basis, approximately 700 patients/families are referred to this clinic for genetic counseling and testing with respect to cancer. In addition, the clinic serves as a center of expertise to 17 regional hospitals and the regional family physicians, yearly handling one to twohundred of their questions by telephone or mail on the possible genetic nature of (combinations) of cancer in a patient/family, in addition to straightforward referrals. The vast majority of referrals to our clinic are for 


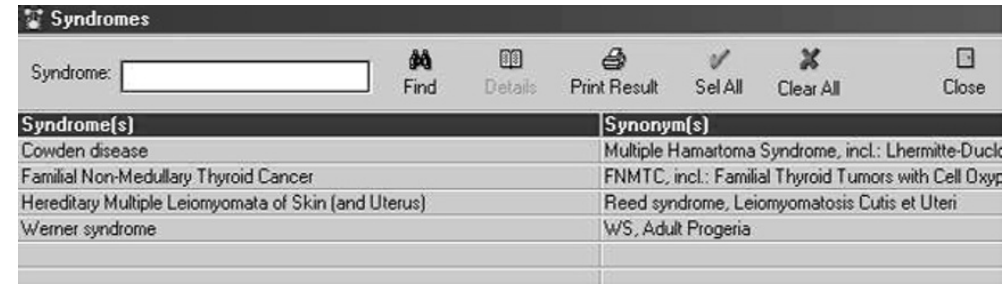

Fig. 2. Screenshot of differential diagnosis returned by FaCD after matching the search profile as seen in Figure 1 with its database contents

(suspected) hereditary breast-(ovarian) cancer (HBOC) or hereditary non-polyposis colorectal cancer (HNPCC), with a steady, but significantly smaller, number of referrals for (suspected) familial adenomatous polyposis, multiple endocrine neoplasia type 1 and 2, Von Hippel-Lindau disease and other familial clustering of cancer or multiple primary tumors. In our setting, $\mathrm{FaCD}$ is rarely used in the many cases of suspected $\mathrm{HBOC}$ or HNPCC, because these referrals usually have been made after meeting a set of clinical criteria that warrant a high suspicion for those particular (suspected) disorders and the differential diagnosis in these cases is well known to our clinical geneticists/genetic counselors. However, FaCD has proven to be helpful in our work as consultants to the regional hospitals and family physicians. A wide range of cancer types observed to cluster in families is reported to our clinic for advice, either by mail or by phone, and $\mathrm{FaCD}$ lends support when deciding if referral to our clinic is warranted. Although, in our clinic, $\mathrm{FaCD}$ is mainly used in the step before possible referral, we regularly use its encyclopedic function by consulting the clinical summaries of the syndromes in the database for extended tumor spectrum and 'facts and figures' that might come in handy during particular counseling sessions. We have recently polled the other Dutch family cancer clinics on their use of $\mathrm{FaCD}$, which revealed that they use the software in a similar way. FaCD has been developed as a tool for experts rather than as an expert system for use by general practitioners and other physicians with limited knowledge of cancer genetics. Increasingly, however, these non-experts in genetics are under pressure to advise their patients on genetic risks, including risks to develop cancer. Therefore, it is important to encourage the development of software to assist them in interpreting family histories of cancer $[14,15]$.

A new version of $\mathrm{FaCD}$ (2.0), with updated database contents, improved user interface, optional saving of the user's search profiles and easy linking to internet sources, is presently under construction and is expected to be released through the internet (www.facd.info) in 2003. User feed back is appreciated (facd@medgen.azg.nl).

\section{References}

1. Lindor NM, Greene MH. The concise handbook of family cancer syndromes. J Natl Cancer Inst 1998; 90 (14): 1039-71.

2. Eeles RA, Ponder BAJ, Easton DF, Horwich Ae. Genetic predisposition to cancer. 1st ed. London: Chapman \& Hall Medical, 1996.

3. Hodgson SV, Maher ER. A practical guide to human cancer genetics. 2nd ed. Cambridge: Cambridge University Press, 1999.

4. Offit K. Clinical cancer genetics. Risk counseling \& management. New York: Wiley-Liss, 1998.

5. Ponz de Leon M. Familial and hereditary tumors. Berlin: SpringerVerlag, 1994.

6. Fischer C, Schweigert S, Spreckelsen C, Vogel F. Programs, databases, and expert systems for human geneticists - a survey. Hum Genet 1996; 97 (2): 129-37.

7. Winter R, Baraitser M. London Dysmorphology Database. Oxford: Oxford University Press, 2001.

8. Bankier A. POSSUM database. Melbourne: The Murdoch Children's Research Institute at the Royal Children's Hospital, 2002.

9. Schinzel A. Human cytogenetics database. Oxford: Oxford University Press, 1994.

10. Sijmons RH, Burger GTN. Familial cancer database: a clinical aide-mémoire. Familial Cancer 2001; 1 (1): 51-5.

11. Salgado LJ, Lopez-Camelo JS, Castilla EE. EL BUSCA and the value of signals in the diagnosis of dysmorphic syndromes: good and bad handles in computer assisted differential diagnosis. J Med Genet 1990; 27 (7): 446-50.

12. Pelz J, Arendt V, Kunze J. Computer assisted diagnosis of malformation syndromes: an evaluation of three databases (LDDB, POSSUM, and SYNDROC). Am J Med Genet 1996; 63 (1): 257-67.

13. Kassirer JP. A report card on computer-assisted diagnosis - the grade: C. N Engl J Med 1994; 330 (25): 1824-5.

14. Emery J, Walton R, Murphy M, Austoker J, Yudkin P, Chapman C, Coulson A, Glasspool D, Fox J. Computer support for interpreting family histories of breast and ovarian cancer in primary care: comparative study with simulated cases. BMJ 2000; 321 (7252): 28-32.

15. Emery J. Computer support for genetic advice in primary care. Br J Gen Pract 1999; 49 (444): 572-5. 